\title{
Analysis on Disease State of Urban Operational Subway Tunnels
}

\author{
Fei Dong ${ }^{1,2}$, Jun Huang ${ }^{1,2, ~ *, ~ A o ~} \mathrm{Li}^{1,2}$, Caichi Gao ${ }^{1,2}$ \\ ${ }^{1}$ Urban Construction \& Railway Design Division, JSTI Group, Nanjing, China \\ ${ }^{2}$ Jiangsu Province Engineering Research Center of Underwater Tunnel Green Intelligent Technology, Nanjing, China \\ Email address: \\ dongfei.21@163.com (Fei Dong), hj130@jsti.com (Jun Huang), la569@jsti.com (Ao Li), gcc891@jsti.com (Caichi Gao) \\ ${ }^{*}$ Corresponding author
}

\section{To cite this article:}

Fei Dong, Jun Huang, Ao Li, Caichi Gao. Analysis on Disease State of Urban Operational Subway Tunnels. Journal of Civil, Construction and Environmental Engineering. Vol. 6, No. 2, 2021, pp. 54-62. doi: 10.11648/j.jccee.20210602.14

Received: March 19, 2021; Accepted: March 29, 2021; Published: April 7, 2021

\begin{abstract}
Structure form, steel bar and service time were considered to be the main factors of the tunnel disease state, based on the disease inspection results of subway tunnels in Beijing. The conclusion indicated that the diseases of shield tunnel such as ovalization of tunnel cross section, lining cracks, crushing and dislocation of duct pieces and water leakage were caused by the deformation of segment joints. Lining crack was the main disease form in monolithic tunnel. The width and depth of cracks were greatly influenced by tunnel operation time and had the characteristics of discreteness and random. Steel bar used in concrete lining could significantly enhance safety of tunnel structures. Water leakage in subway tunnel was influenced by rainfall and usually could be observed at the gaps of tunnel structures, such as bolt holes and segment joint of shield tunnel or the construction joints, deformation joints and lining cracks of monolithic tunnel. The most lining cavities were found located at the vault and the cavity shape was similar to strip, square or oval with lining cracking nearby. The carbonation depth of lining concrete was proportional to tunnel operation time and its value and speed at ballast bed was most, sidewall less and vault least. It is hoped that the results can provide some reference for the disease law analysis and treatment of urban tunnel.
\end{abstract}

Keywords: Subway Tunnel, Disease, Shield Tunnel, Monolithic Tunnel, Crack, Water Leakage

\section{Introduction}

It's shown by the daily inspection results and maintenance work that the structural defections are all over the subway tunnels in service. Structural defections have important influence on the security of subway tunnels in service. At present, the research on subway tunnel structural defections mainly focuses on grading and classification of defections, the cause analysis of defections under special geological conditions and the research and treatment technology for a specific defection.

Zhang [1] based on the survey results of Nanjing Subway, classified the subway tunnel defections into longitudinal settlement, crack, seepage and ballast bed separation. Ye [2] analyzed the causes of defections based on the monitoring data of longitudinal unequal settlement in the tunnel of Shanghai Subway Line 1. Lin et al. [3] analyzed the factors affecting the longitudinal deformation of subway tunnels from the aspects of construction, geology and external disturbance. Zhu et al. [4] analyzed the reasons for cracks of shield tunnel from three aspects of production, construction and service. Qiu et al. [5], Liu et al. [6] analyzed the defections such as segment cracks and dislocation of segments caused by unequal stress on segments due to water gushing. Wu et al [7] studied the field leaking behavior of different shield tunnels under the Huangpu River and discuss the factors influencing the water tightness of tunnels. Luo [8] studied the cracking mechanism and control method of tunnel lining cracks based on fracture mechanics. Based on model tests and numerical simulations of Beijing Subway tunnel reinforced with fiber cloth, $\mathrm{Li}$ et al. [9] studied the reinforcing effect. $\mathrm{Li}$ [10] discussed the classification standard and reinforcement measures of subway tunnel diseases constructed by mine method. From aspects of construction and hydrogeology, Zhong et al. [11] analyzed the mechanism of separation, void and slurry pouring of ballast bed, and proposed corresponding remedial measures 
for void and crack of the ballast bed. Zhao et al. [12] conducted a special study on the mechanism of seepage, crack, and separation of subway ballast bed and provided an evaluation system. Cao et al. [13] proposed the reinforcement and repair technology of segment crack and damage based on a case study. The existing studies lack the analysis of the damage state and influencing factors from the aspect of data, the influence of lining structure form on the damage, and the research on concrete carbonation which affects the durability of the structure.

In this paper, subway tunnels are divided into two types: the monolithic tunnel which is lined with cast-in-place concrete and the shield tunnel which is assembled with segments. Based on the special inspection data of typical lines of Beijing Subway, the main disease states of two types of tunnels are analyzed. The diseases of subway tunnels are divided into over-limit deformation of shield tunnel, lining damage, water leakage, and ballast bed damage. The results show that the damage state of subway tunnel is greatly affected by the structure form of tunnel, the proximity construction, service time, concrete reinforcement and the location of measurement points. The results show that the damage state of subway tunnel in service should be considered as an important factor in the selection of construction methods during construction period.

\section{Over-limit Deformation of the Shield Tunnel Cross-section}

Shield tunnel is made up of prefabricated segments and connected by bolts. Shield tunnel structure has a large number of joints, resulting in a weak ability to resist deformation. The deformation of the structure under external load is mainly manifested as the ovalization of the cross section caused by the mutual dislocation and extrusion of adjacent segments. The large ovalization of the cross section leads to the penetration of the tunnel contour, which affects the safety of subway trains. At the same time, the ovalization of cross section changes the stress state of the structure and induces the segment damage. The deformation of segment joints leads to the failure of the waterproof function of structure, and causes serious water leakage in the area with abundant groundwater.

Ovality is used to measure the degree of ovalization of shield tunnel cross section. Ovality is defined as the difference between the long axis and the short axis of the actual cross section shape. Because of the flexible character of shield tunnel, ovalization is a common phenomenon in shield tunnel. Taking the inspection data of a shield tunnel cross section of Beijing Subway Line 15 as an example. The tunnel is located in the northeast of Beijing, underpasses the existing river. The outer diameter of the shield tunnel is $6 \mathrm{~m}$, and the reconstruction of the existing bridge is carried out on the south side of the adjacent area. The inspection range is the west bank roadbed section, the bridge section and the east bank roadbed section, with a total of 219 shield tunnel sections of $1015 \mathrm{~m}$.

The statistical results of the ovality inspection data of the three-part tunnel intervals in this area are shown in Table 1. According to Shield Tunneling Construction and Acceptance Code [14], the limit of the ovality of subway shield tunnel is $\pm 6 \%$ of the outer diameter of shield tunnel, where $36 \mathrm{~mm}$ is taken. The direction of the ovalization section is indicated by the included angle between the long axis and the vertical direction, as shown in Table 2.

Table 1. Statistic of ovality of shield tunnels cross-section in Beijing Subway Line 15.

\begin{tabular}{|c|c|c|c|c|c|}
\hline Interval & Direction & Maximum value/ mm & Minimum value/ mm & Mean value/ mm & Over-limit rate \\
\hline \multirow{2}{*}{ West bank subgrade } & right & 72 & 5 & 35.65 & $30.00 \%$ \\
\hline & left & 55 & 10 & 29.36 & $9.09 \%$ \\
\hline \multirow{2}{*}{ Bridge } & right & 86 & 6 & 33.84 & $39.22 \%$ \\
\hline & left & 45 & 2 & 24.61 & $12.20 \%$ \\
\hline \multirow{2}{*}{ East bank subgrade } & right & 63 & 2 & 27.39 & $18.18 \%$ \\
\hline & left & 36 & 3 & 22.69 & 0 \\
\hline
\end{tabular}

Table 1. Statistic of ovality direction of shield tunnel cross-section in Beijing Subway Line 15.

\begin{tabular}{|c|c|c|c|c|}
\hline Interval & Direction & Maximum value & Minimum value & Mean value \\
\hline \multirow{2}{*}{ West bank subgrade } & right & $96^{\circ} 39^{\prime} 08^{\prime \prime}$ & $28^{\circ} 49^{\prime} 52^{\prime \prime}$ & $79^{\circ} 57^{\prime} 13^{\prime \prime}$ \\
\hline & left & $101^{\circ} 52^{\prime} 39^{\prime \prime}$ & $32^{\circ} 04^{\prime} 06^{\prime \prime}$ & $79^{\circ} 37^{\prime} 57^{\prime \prime}$ \\
\hline \multirow{2}{*}{ Bridge } & right & $101^{\circ} 12^{\prime} 26^{\prime \prime}$ & $60^{\circ} 16^{\prime} 51^{\prime \prime}$ & $85^{\circ} 30^{\prime} 50^{\prime \prime}$ \\
\hline & left & $104^{\circ} 54^{\prime} 30^{\prime \prime}$ & $48^{\circ} 15^{\prime} 16^{\prime \prime}$ & $80^{\circ} 25^{\prime} 55^{\prime \prime}$ \\
\hline \multirow{2}{*}{ East bank subgrade } & right & $126^{\circ} 08^{\prime} 52^{\prime \prime}$ & $10^{\circ} 47^{\prime} 40^{\prime \prime}$ & $72^{\circ} 50^{\prime} 25^{\prime \prime}$ \\
\hline & left & $107^{\circ} 41^{\prime} 15^{\prime \prime}$ & $13^{\circ} 25^{\prime} 48^{\prime \prime}$ & $79^{\circ} 38^{\prime} 13^{\prime \prime}$ \\
\hline
\end{tabular}

According to the statistical results of ovality, ovalization deformation appears in all examined sections, and there are big differences in ovality. Except for the left direction of the east bank roadbed section, the ovality of each section appears to exceed the limit. The highest over-limit rate is found in the right direction of the bridge section, which reaches $39.22 \%$. Although there is no over-limit in the east bank roadbed section, the section whose the ovality exceeds $\pm 5 \%$ o ( $30 \mathrm{~mm})$ of the tunnel outer diameter accounts for $25 \%$ of the total inspected section. Under the influence of bridge reconstruction, the over-limit rate of the tunnel section of upper routine is greater than that of the lower one. The over-limit rate of the bridge section is greater than that of the roadbed section on both sides. 
Affected by the bearing capacity of each segment and the complicated construction conditions, the direction of the ovalization section in inspection range varies greatly. The maximum difference of the angle between the long axis and the vertical direction is $115^{\circ} 21^{\prime} 12^{\prime \prime}$.

\section{Lining Diseases of Subway Tunnels}

The types of lining diseases of subway tunnels include lining crack, concrete carbonization, and lining cavity. Due to different structure forms, the conditions of tunnel linings are different.

\subsection{Lining Crack}

\subsubsection{Overview of Lining Crack}

Crack of lining concrete is the most common disease in subway tunnels. The proportion of lining crack in the total damage is related to the form of lining structure. In general, the lining crack of monolithic tunnel accounts for the vast majority of the total damage, while that of shield tunnel is contrary.

The distribution of the types of diseases in shield tunnel section of Beijing Subway is shown in Figure 1 (a). The inspection range is $112.7 \mathrm{~km}$, covering 7 lines such as Line 5, among which only $4 \%$ of the diseases are segment crack. The disease distribution of the tunnel of Beijing Subway Line 1 and Line 2 with a total length of $51.4 \mathrm{~km}$ is shown in Figure 1 (b). More than $98 \%$ of the diseases are lining crack. In the line with transit shield tunnel, the proportion of lining crack to the total damage decreases with the increase of the length ratio of transit shield tunnel. For example, the lines including transit shield tunnels built in Beijing after 2007 all appear this rule.

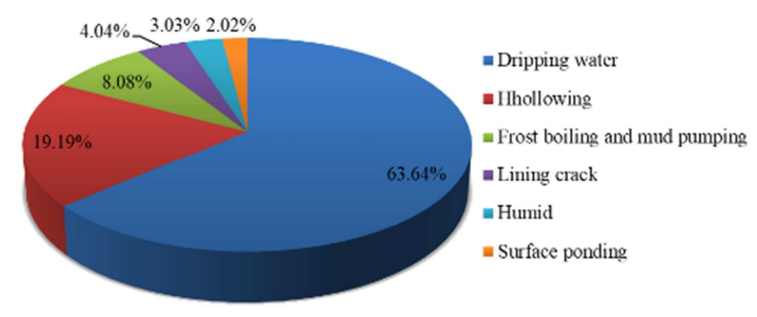

(a) Shield tunnel

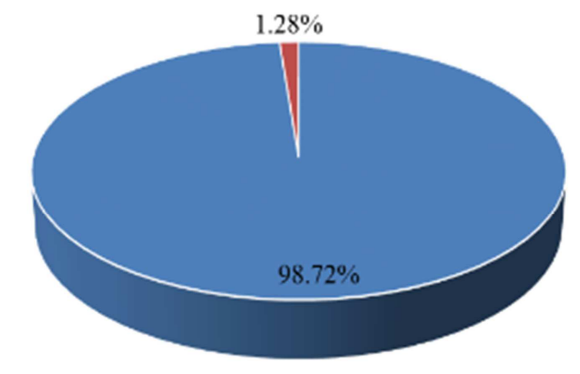

" number of Crack disease " number Other disease

(b) Monolithic tunnel

Figure 1. Disease distribution in two different tunnels.
The lining cracks direction of monolithic tunnel include four kinds: longitudinal, circular, synclinal, and reticular. Except for reticular cracks, lining cracks mostly occur in the form of main cracks, namely, there is only one obvious visible crack in a certain area, and two visible cracks have a certain distance. The lining cracks of shield tunnels are mainly manifested as dense longitudinal cracks in the middle of segments, cracks of concrete near joints and cracks through bolt holes. The cracks of monolithic tunnel lining of Beijing Subway Line 1 and Line 6 are shown in Figure 2. Segment cracks of a shield tunnel in the Beijing Subway Airport Line are shown in Figure 3.

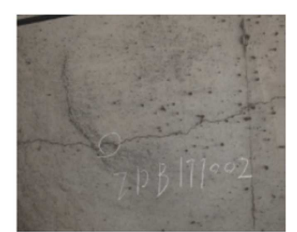

(a) Longitudinal crack

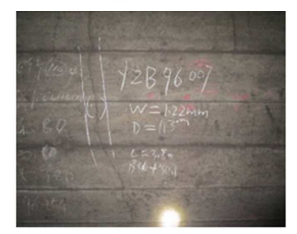

(c) Inclined crack

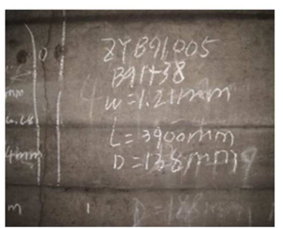

(b) Circumferential crack

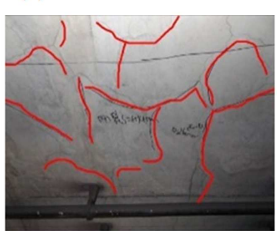

(d) Map cracking
Figure 2. Lining crack types at monolithic tunnel.

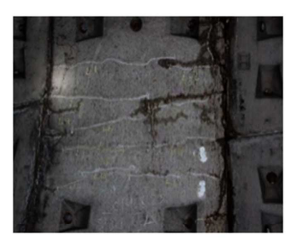

(a) Segment Longitudinal crack

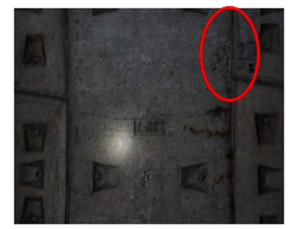

(c)Block falling near the joint

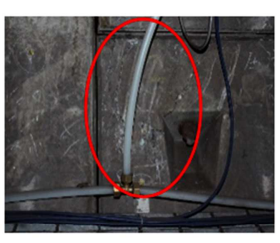

(b) Segment Crushing

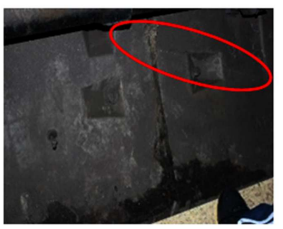

(d) Penetrating crack of bolt hole
Figure 3. Crack types of shield segments.

Research shows that the generation and expansion of concrete cracks are accompanied by the accumulation and release of energy [15]. After cracks are generated, the nearby concrete is unloaded. It is only when new energy accumulates that new cracks appear. The load-bearing, deformation and crack expansion of a monolithic tunnel take the section between the deformation joints as the unit. From the point of view of tunnel cross-section and longitudinal scale, two cracks will be a certain distance apart. Deformation and cracks of shield tunnel take segment as a unit, and the scale is much smaller than that of monolithic tunnel. So the cracks in the 
middle of the segment are more dense. At the same time, the stress of shield tunnel is similar to the plane strain problem. Cracks of the segment are mainly caused by the load in the plane of the cross-section, and cracks in the middle of the segment is shown as longitudinal cracks. In addition, the uneven distribution of jack thrust on the shield segment during construction is also an important reason for longitudinal cracks.

Segment is the carrier of shield tunnel, and the boundary conditions of segments are composed of joints and bolts. After the structure is loaded, it is firstly manifested as opening and squeezing or dislocation of joints, which leads to the dislocation of segments (Figure 4) and the ovalization deformation. In this case, the boundary conditions can be regarded as plastic hinge supports. When the displacement of joint is completely limited, the deformation of segment itself will appear, and the continuous development will lead to the cracks of segment. At this time, the boundary is the fixed end support. The existence of bolt holes and hand holes weakens the bearing area of segment. When the extrusion pressure caused by joint compaction exceeds the bearing capacity of concrete, it will cause the collapse of concrete near the bolt holes, the drop of concrete blocks between joints and cracks through the bolt holes.

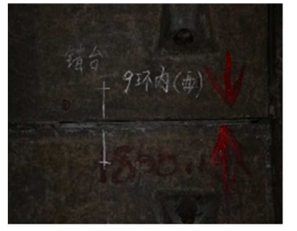

(a) Dislocation of segment longitudinal joints

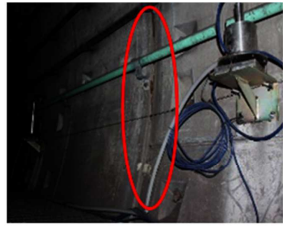

(b) Dislocation of segment circumferential joints
Figure 4. Dislocation of shield segments.

\subsubsection{Influence of Reinforcement on Cracks of Lining}

Beijing Subway Line 1 consists of two parts. The first part, built in 1965-1969, is called 'Old Line 1'. It covers the section from Ping guo yuan Station to $\mathrm{Fu}$ xing men Station and is lined with reinforced concrete with a rectangular cross-section. The second part, built in 1992, is called 'Fu Ba Line". It covers the section from Fuxing men Station to Sihuidong Station, and adopts plain concrete secondary lining with horseshoe cross-section.

The presence of steel bars in concrete structures can significantly reduce the stress intensity factor at crack end and the displacement of crack opening, which has a great effect on limiting the development of cracks [16]. From the actual inspection results, the presence of steel bars has a great influence on distribution of the direction, width and depth of lining cracks.

The inspection results show that the directions of cracks in the lining of 'Old Line 1' are circular. The directions of cracks in the lining of ' $\mathrm{Fu} \mathrm{Ba}$ Line' are divided into circular direction and longitudinal direction. The number of longitudinal cracks in a inspection interval of ' $\mathrm{Fu}$ Ba Line' accounts for $72.49 \%$ of the total number of cracks. The stress of tunnel structure is a plane strain problem, and the bearing capacity of typical cross-section is considered in the design of structure. So longitudinal crack is the most dangerous form in the tunnel structure. The larger the proportion of longitudinal cracks is, the more disadvantageous it is to the safety of tunnel structure.

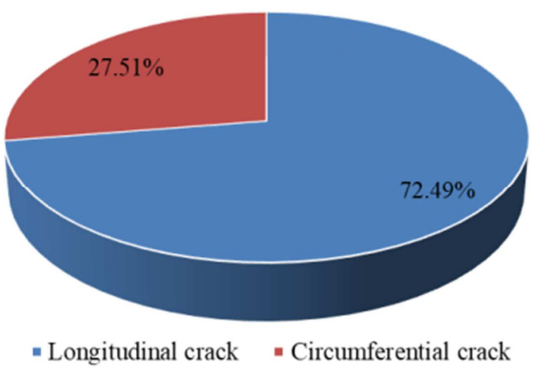

Figure 5. Direction distribution of lining cracks in an interval of Fuxingmen to Sihui section.

The distribution of crack width in the lining of 'Old Line 1' and 'Fu Ba Line' shown in Figure 6 and Figure 7, respectively ( $\mathrm{K}$ represents crack width). The proportion of cracks with width greater than $1 \mathrm{~mm}$ on plain concrete lining is greater than that on reinforced concrete lining. The proportion of cracks with width greater than $1.5 \mathrm{~mm}$ in plain concrete secondary lining reaches $6.25 \%$, much higher than that in reinforced concrete secondary lining $(1.49 \%$ and $3.37 \%)$. The crack width is one of the criteria to judge the stability of the structure. The larger the proportion of the wide cracks is, the lower the safety of the structure is.

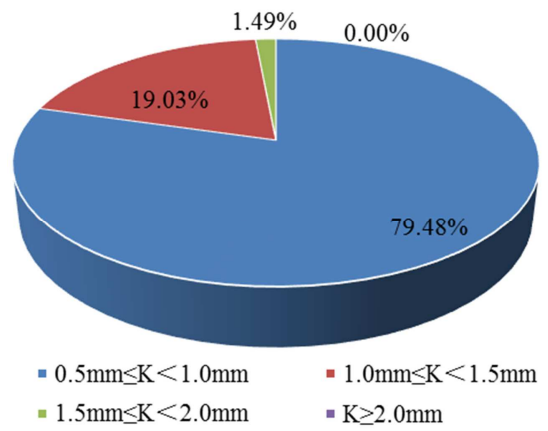

(a) Interval 1

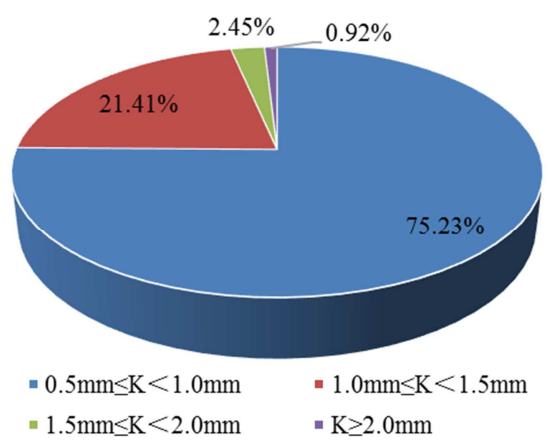

(b) Interval 2

Figure 6. Width distribution of lining cracks in two intervals of Pingguoyuan to Fuxingmen section. 


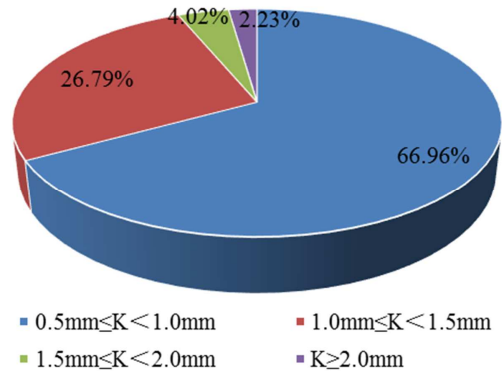

Figure 7. Width distribution of lining cracks in an interval of Fuxingmen to Sihui section.
The distribution of crack depth is shown in Table 3. The existence of steel bars in lining concrete causes the width of cracks to be distributed in a certain interval. For example, the crack width in section 1 mainly concentrates in $75 \sim 150 \mathrm{~mm}$, and that in section 2 mainly concentrates in 100 225 mm. The cracks of concrete are mainly affected by load. The crack distribution interval of plain concrete lining without reinforcement is more average and random.

Table 3. Depth distribution of lining cracks in some intervals of Beijing Subway Line 1.

\begin{tabular}{llll}
\hline Depth of lining cracks/ mm & Interval 1 of 'Old Line 1' & Interval 2 of 'Old Line 1' & Interval of 'Fu Ba Line' \\
\hline$<25$ & 0 & 0 & 0 \\
{$[25,50)$} & $2.98 \%$ & 0 & $6.11 \%$ \\
{$[50,75)$} & $5.40 \%$ & $0.31 \%$ & $11.79 \%$ \\
{$[75,100)$} & $17.13 \%$ & $4.59 \%$ & $6.11 \%$ \\
{$[100,125)$} & $27.93 \%$ & $15.90 \%$ & $5.68 \%$ \\
{$[125,150)$} & $12.66 \%$ & $15.90 \%$ & $12.66 \%$ \\
{$[150,175)$} & $8.94 \%$ & $12.54 \%$ & $10.92 \%$ \\
{$[175,200)$} & $8.01 \%$ & $8.87 \%$ & $11.35 \%$ \\
{$[200,225)$} & $5.96 \%$ & $18.35 \%$ & $10.92 \%$ \\
{$[225,250)$} & $3.35 \%$ & $9.48 \%$ & $6.99 \%$ \\
{$[250,275)$} & $3.91 \%$ & $7.34 \%$ & $6.55 \%$ \\
{$[275,300)$} & $3.35 \%$ & $5.50 \%$ & $10.92 \%$ \\
$>300$ & $0.37 \%$ & $1.22 \%$ & 0 \\
\hline
\end{tabular}

The arch structure with horseshoe section can bear only compressive force and give full play to the compressive performance of concrete under the condition of reasonable arch axis. But the stratum condition is complicated, a single cross-section can not meet all geological conditions, coupled with the impact of train vibration, plain concrete lining structure will inevitably bear tensile force, resulting in structural cracks. In addition, plain concrete is brittle material, the deformation limit is very small, and there is no warning before the structural failure. Therefore, plain concrete should not be used in the secondary lining.

\subsubsection{Crack State of Beijing Subway Tunnel Linings}

'Old Line 1', 'Fu Ba Line' and the first phase of Line 10 of Beijing subway have been in service for 45 years, 16 years and 8 years respectively. The statistical results of the width and depth of cracks in the lining of some interval tunnels of the above-mentioned lines are shown in Table 4. The statistical results contain inspection results of 1142 lining cracks. The statistical results of crack width show that the mean crack width of each line has little difference. The larger standard deviation and coefficient of variation indicate that the crack width and the degree of dispersion are greatly affected by the service time. Due to the long service time and the influence of surrounding environmental factors during the service period, the tunnel lining in the interval contains cracks at various development stages. According to the data, the maximum crack width and coefficient of variation in the three intervals of Line 1 are larger than those of Line 10. There are many factors affecting the crack width. The crack width of all tunnel linings in the statistical range doesn't concentrate on a certain value, which has a strong randomness. The minimum crack width of each interval is about $0.5 \mathrm{~mm}$, except for the two intervals of the left direction tunnel of 'Old Line 1'. The maximum crack width of each interval is located in the right direction tunnel on the 'Fu Ba Line', reaching $3.57 \mathrm{~mm}$.

Table 4. Statistic of width and depth of lining cracks in some intervals of Beijing Subway.

\begin{tabular}{|c|c|c|c|c|c|c|c|c|c|}
\hline \multirow[b]{2}{*}{ Interval } & \multirow[b]{2}{*}{ Direction } & \multicolumn{3}{|l|}{ Width / mm } & \multicolumn{3}{|l|}{ Depth / mm } & \multirow[b]{2}{*}{ Percent/ \% } & \multirow{2}{*}{$\begin{array}{l}\text { Density / } \\
\text { strip/m }\end{array}$} \\
\hline & & Mean value & $\begin{array}{l}\text { Maximum } \\
\text { value }\end{array}$ & $\begin{array}{l}\text { Minimum } \\
\text { value }\end{array}$ & Mean value & $\begin{array}{l}\text { Maximum } \\
\text { value }\end{array}$ & $\begin{array}{l}\text { Minimum } \\
\text { value }\end{array}$ & & \\
\hline Interval 1 of 'Old & Right & 0.77 & 1.77 & 0.50 & 97.49 & 197 & 32 & 0 & 0.144 \\
\hline Line 1 , & Left & 0.85 & 1.81 & 0.29 & 176.67 & 367 & 73 & 0 & 0.158 \\
\hline Interval 2 of 'Old & Right & 0.86 & 2.85 & 0.46 & 186.64 & 331 & 75 & 2.4 & 0.124 \\
\hline Line 1' & Left & 0.88 & 2.91 & 0.05 & 176.82 & 374 & 70 & 0.6 & 0.125 \\
\hline Interval of ' $\mathrm{Fu} \mathrm{Ba}$ & Right & 0.98 & 3.57 & 0.50 & 139.22 & 298 & 25 & 40.6 & 0.079 \\
\hline Line' & Left & 0.90 & 2.2 & 0.50 & 184.93 & 299 & 30 & 71.2 & 0.109 \\
\hline Interval 3 of Line 10 & Left & 0.71 & 0.93 & 0.56 & 100.7 & 126 & 84 & 0 & 0.011 \\
\hline Interval 4 of Line 10 & Left & 0.61 & 0.9 & 0.51 & 107.3 & 151 & 40 & 0 & 0.018 \\
\hline Interval 5 of Line 10 & Left & 0.73 & 1.15 & 0.51 & 107.7 & 151 & 82 & 0 & 0.018 \\
\hline
\end{tabular}


The average crack depth of each line has large difference, which basically shows that the longer the service time is, the greater the depth is. Similar to the crack width, the crack depth is also very discrete and random. Due to the different lining thickness, the maximum crack depth is located in the tunnel of 'Old Line 1'. Percentage in the table refers to the ratio of the number of cracks with a depth greater than half of the lining thickness to the total number of cracks. On the whole, the cracks of "Fu Ba Line" are the most serious. There are 40.6\% and $71.2 \%$ cracks in the right and left direction lines respectively, whose depth exceeds half of the lining thickness. The deepest reaches $99 \%$ of the lining thickness. The inspection results also show that the maximum crack length in the interval of ' $\mathrm{Fu} \mathrm{Ba}$ Line' is much larger than that in other intervals. The maximum crack length of the right direction line reaches $202.2 \mathrm{~m}$, and the direction is longitudinal.

From the results of crack density, it can be seen that the crack density gradually decreases with the decrease of service time, and the crack density in the same period is in the same order of magnitude. Although the service time of the ' $\mathrm{Fu} \mathrm{Ba}$ Line' is nearly 30 years less than that of 'Old Line 1', there is little difference in the crack state between the two lines because the plain concrete secondary lining is used in the 'Fu Ba Line'.

Because of the complex stress of tunnel structure, the inspected cracks include tensile cracks and shear cracks. Therefore, the average crack width of each line has little difference, while the average crack depth has great difference.

\subsection{Carbonization of Lining Concrete}

Concrete material reacts with carbon dioxide in the environment to produce carbonization, which reduces the alkalinity inside the concrete. Carbonization mainly leads to corrosion of reinforcement, increases the brittleness of the structure, and reduces the bearing capacity and safety of the structure [17].

Table 5. Statistic of carbonation depth of lining concrete in some intervals of Beijing Subway.

\begin{tabular}{|c|c|c|c|c|c|}
\hline Interval & Built time & Direction & Point location & Mean value/ mm & Carbonation rate/ $\mathrm{mm} / \mathbf{a}$ \\
\hline \multirow{4}{*}{ Interval 1 of 'Old Line 1' } & \multirow{4}{*}{1971} & \multirow{2}{*}{ Right } & Left wall & 10.62 & 0.25 \\
\hline & & & Right wall & 11.06 & 0.26 \\
\hline & & \multirow{2}{*}{ Left } & Left wall & 10.00 & 0.23 \\
\hline & & & Right wall & 10.86 & 0.25 \\
\hline \multirow{5}{*}{ Interval of 'Fu Ba Line' } & \multirow{5}{*}{1999} & \multirow{3}{*}{ Right } & North wall & 8.48 & 0.71 \\
\hline & & & Crown & 4.05 & 0.34 \\
\hline & & & South wall & 7.76 & 0.65 \\
\hline & & \multirow[t]{2}{*}{ Left } & Crown & 4.22 & 0.35 \\
\hline & & & South wall & 7.31 & 0.61 \\
\hline \multirow{6}{*}{$\begin{array}{l}\text { Interval } 3 \text { of Line } 10 \\
\text { (open-cut) }\end{array}$} & \multirow{6}{*}{2008} & \multirow{3}{*}{ Right } & Left wall & 2.61 & 0.52 \\
\hline & & & Crown & 2.39 & 0.48 \\
\hline & & & Right wall & 2.33 & 0.47 \\
\hline & & \multirow{3}{*}{ Left } & Left wall & 2.67 & 0.53 \\
\hline & & & Crown & 2.17 & 0.43 \\
\hline & & & Right wall & 2.61 & 0.52 \\
\hline \multirow{5}{*}{$\begin{array}{l}\text { Interval } 3 \text { of Line } 10 \\
\text { (underground-cut) }\end{array}$} & \multirow{5}{*}{2008} & \multirow[t]{3}{*}{ Right } & Crown & 2.40 & 0.48 \\
\hline & & & Right wall & 2.52 & 0.50 \\
\hline & & & Left wall & 2.76 & 0.55 \\
\hline & & Left & Crown & 2.40 & 0.48 \\
\hline & & & Right wall & 2.67 & 0.53 \\
\hline \multirow{2}{*}{ Interval of Line 9} & \multirow{2}{*}{2011} & Right & Side wall & 2.02 & 0.67 \\
\hline & & Left & Side wall & 2.19 & 0.73 \\
\hline \multirow{6}{*}{ Interval 6 of Line 6} & \multirow{6}{*}{2012} & \multirow{3}{*}{ Right } & Left wall & 1.75 & 0.88 \\
\hline & & & Crown & 1.25 & 0.63 \\
\hline & & & Right wall & 2.00 & 1.00 \\
\hline & & \multirow{3}{*}{ Left } & Left wall & 1.63 & 0.81 \\
\hline & & & Crown & 1.13 & 0.56 \\
\hline & & & Right wall & 1.75 & 0.88 \\
\hline \multirow{4}{*}{ Interval 7 of Line 15} & & \multirow[b]{2}{*}{ Right } & Left wall & 1.90 & 0.63 \\
\hline & & & Ballast bed & 2.56 & 0.85 \\
\hline & & \multirow[t]{2}{*}{ Left } & Ballast bed & 2.50 & 0.83 \\
\hline & & & Right wall & 2.00 & 0.67 \\
\hline
\end{tabular}

The carbonization depth measurement results of 4719 points in 14 intervals of 5 subway lines in Beijing were analyzed. The statistical results of typical inspection data of carbonation depth in some intervals of Beijing subway are shown in Figure 5. The statistical results cover the carbonization depth measurement values of multiple lines in each construction period of Beijing subway, including different cross-section forms and construction methods. 
Inspection locations in most intervals include side walls and crowns. Except for Line 6 and Line 15, the coefficient of variation of statistical results of other lines is small, and the dispersion of statistical results is not large.

The statistical results show that the carbonation depth of concrete is most affected by service time. The carbonization depth of lining concrete of 'Old Line 1' is more than $10 \mathrm{~mm}$ on average. The carbonation depth of the side wall concrete of ' $\mathrm{Fu} \mathrm{Ba}$ Line' tunnel is $7.3-8.5 \mathrm{~mm}$, and the carbonation depth of the crown is about $4 \mathrm{~mm}$. The carbonization depth of new lines after 2008 is $1.1-2.8 \mathrm{~mm}$. In intervals containing the measuring points of the crown, except for the interval 3 of the Line 10, other intervals all show a trend that the average carbonation depth and carbonation rate of crowns are smaller than those of side walls. The carbonation depth and carbonation rate of side walls of the interval 7 of the Line 15 are less than those of ballast bed. Preliminary analysis suggests that this phenomenon is due to higher concentration of carbon dioxide in the lower part of tunnel. The average depth and rate of carbonation of open-cut and underground-cut intervals in the interval 3 of line 10 have little difference, which indicates that the construction method have little influence on the carbonation depth. The statistical results of carbonization data for the right and left direction tunnels of the same line are not significantly different. The carbonation depth of the concrete of each line doesn't exceed the thickness of the protective layer of the reinforced concrete lining.

\subsection{Cavities in Linings}

Due to the effect of gravity, it is difficult to guarantee the pouring quality of second lining crowns, which leads to the occurrence of cavities in tunnel lining crowns. Among the 48 cavities inspected in the tunnel of Beijing Subway Line 6, all of them are located in crowns except for one of them located at shoulder.

The shapes of the cavities in linings include strip, square, and oval. In the inspection range, the longitudinal length of cavities is $0.15-3.8 \mathrm{~m}$, the circular length is $0.3 \sim 3 \mathrm{~m}$, the depth is $0.05-0.43 \mathrm{~m}$, and the area is $0.125-11.68 \mathrm{~m}^{2}$. Among them, the cavities with longitudinal length of $0.4-0.5 \mathrm{~m}$ and $1.1-1.2 \mathrm{~m}$ were the most, accounting for $12.5 \%$ of the total number of cavities. The cavities with circular length of $0.4-0.5 \mathrm{~m}$ were the most, accounting for $16.7 \%$ of the total number of cavities. The cavities with area less than $2 \mathrm{~m}^{2}$ account for $74.5 \%$ of the total number of cavities. The cavities in linings lead to stress concentration phenomenon and cause lining cracks. Cracks of lining concrete near cavities in the inspection process are shown in Figure 8.

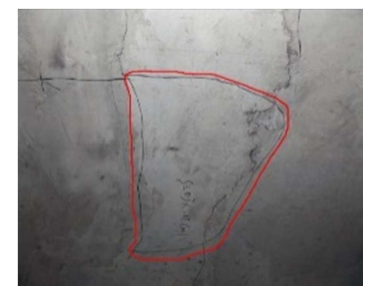

Figure 8. Lining cracks around the hole at arch crown.

\section{Water Leakage in Subway Tunnels}

The formation of water leakage in subway tunnels needs to meet the two conditions of water accumulation point and water flow channel in the stratum. The 'channel' here consists of stratum channel (permeable stratum) and tunnel lining structural channel.

The waterproofing system of monolithic tunnel is composed of concrete self-waterproofing and waterproofing sheets laid between primary support and secondary lining [18] The leakage channels of tunnel structure mainly come from the joints formed by the construction of waterproof sheets, damage of waterproof sheets caused by binding and welding of steel bars in secondary lining, structure construction joints, deformation joints, cracks of linings and waterproof performance of concrete. The water leakage in monolithic tunnels mainly appears in deformation joints, construction joints and cracks of linings. When there are water accumulation points in stratum, the leakage situation of monolithic tunnels are shown in Figure 9.

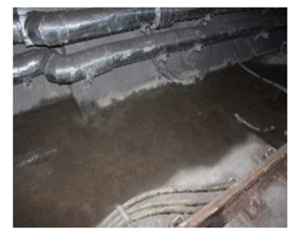

(a) Floor leakage

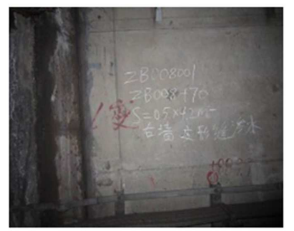

(c) Deformationjoint leakage

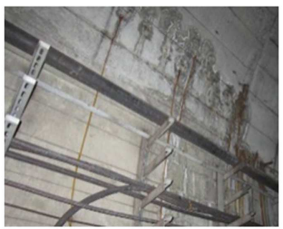

(b) Side wall leakage

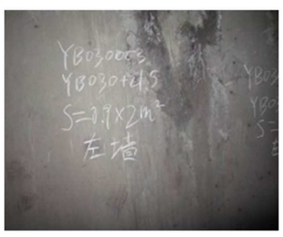

(d) Crack leakage
Figure 9. Water leakage at monolithic tunnels.

The waterproof system of shield tunnels includes the waterproof gaskets between segments, the synchronous grouting rings during construction and the waterproof performance of segments. Shield tunnels are composed of segments. There are a large number of circular joints, longitudinal joints, bolt holes and grouting holes. These joints and holes are potential water leakage channels in shield tunnels. The opening of segment joints and dislocation of segments caused by the deformation of shield tunnel will have a great influence on the waterproof performance of shield tunnels. When the dislocation exceeds a certain value, the waterproof gaskets are no longer overlapped, resulting in waterproof failure. Once there are water accumulation points in stratum, the leakage situation in shield tunnels will be very serious and difficult to deal with. The field investigation results show that $77 \%$ of the damage in shield tunnels is related to water leakage (as shown in Figure 1). The leakage situation of a shield tunnel in Beijing subway is shown in Figure 10. It can be seen that the location of leakage is mainly concentrated in joints and bolt holes mentioned above, and 
water leakage is mainly distributed below the waist of tunnels.

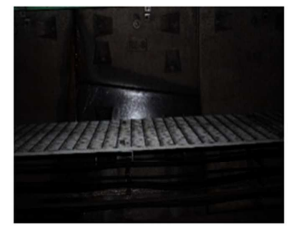

(a) Segment longitudinal joint leakage

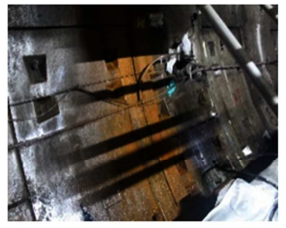

(b) Segment Circumferential

joint leakage
Figure 10. Water leakage at a shield tunnel of Beijing subway.

In addition, the degree of water leakage is also related to local precipitation in a certain period of time. The leakage situation of the same location in a shield tunnel of Beijing subway in different seasons is shown in Figure 11. The rainy season in Beijing is usually from June to September. It can be clearly seen from the two figures that during the rainy season, there are more locations of water leakage and wider range of water leakage in the tunnel and the inner space of the tunnel is wetter.

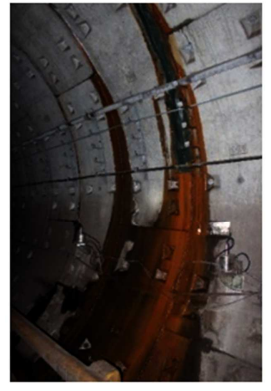

(a) Early November

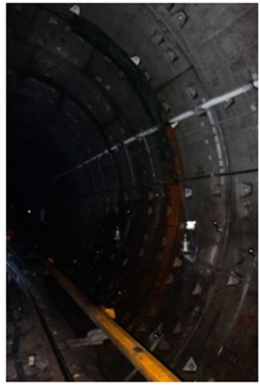

(b) Late August
Figure 11. Water leakage in different seasons at a shield tunnel of Beijing subway.

\section{Conclusions}

Based on the on-site inspection results, this paper analyzes the disease status of Beijing subway tunnels in service and draws the following conclusions:

(1) Deformation of segment joints is an important cause of diseases of shield tunnels. Deformation of segment joints causes the oval deformation of shield cross-sections, the collapse and dislocation of segments, and water leakage. Water leakage is mainly located in segment joints and bolt holes, and greatly affected by precipitation.

(2) Crack of lining is the main disease of monolithic tunnel. The width and depth of cracks are greatly affected by the service time, and characterized by strong dispersion and randomness. Concrete reinforcement has positive effect on safety of tunnel. Water leakage is mainly located in deformation joints, construction joints and position of lining cracks.

(3) Cavities of linings are usually located in crowns, and their shapes are nearly strip, square and oval, and usually accompanied by cracks in linings. The carbonation depth and rate of concrete are the largest in ballast beds, the second in side walls and the lowest in crowns.

\section{Acknowledgements}

This work was supported by the Fundamental Research Funds for Key Research and Development Programs of Jiangsu under Grant BE2020082-2 and Science \& technology projects of Jiangsu construction system under Grant $2019 Z D 116$.

\section{References}

[1] Zhang Xuewen. (2014) Research on the causes and treatment methods of common diseases during the operation of subway tunnel structure. Nanjing University.

[2] YE Yao-dong, ZHU He-hua, WANG Ru-lu. (2007) Analysis on the Current Status of Subway Operating Tunnel Damage in Soft Ground and Its Causes. Chinese Journal of Underground Space and Engineering, 3 (1): 157-160.

[3] LIN Yongguo, LIAO Shaoming, LIU Guobin. (2000) Discuss on Influence Factors of Longitudinal Deformation in Subway tunnel. Underground Space, 20 (4): 264-267.

[4] Zhu Weibin, Ju Shijian. (2003) Causes and countermeasures for segment cracking in shield-driven tunnel. Modern Tunnelling Technology, 40 (1): 21-25.

[5] Qiu Junling, Lu Yuquan, Lai Jinxing, Guo Chunxia, Wang Ke, (2020) Failure behavior investigation of loess metro tunnel under local-high-pressure water environment. Engineering Failure Analysis. 115, 104631.

[6] Liu C, Lai J X, Liu Q. (2013) A Review of Research Situation on Shield Tunnel Diseases. Applied Mechanics \& Materials, 438-439: 943-948.

[7] Wu, HN., Huang, RQ., Sun, WJ. et al. (2014) Leaking behavior of shield tunnels under the Huangpu River of Shanghai with induced hazards. Nat Hazards 70, 1115-1132. https://doi.org/10.1007/s11069-013-0863-z.

[8] Luo Yong. (2011) Study on the Mechanism of Crack Generation and Control Methods of Tunnelling. SOUTHWEST JIAOTONG UNIVERSITY.

[9] Li Yujie, Wang Mengshu, Xu Huijie et al. (2014) Numerical analysis of subway tunnel structure reinforced with fiber cloth material. CHINA CIVIL ENGINEERING JOURNAL, 47 (8): 138-144.

[10] Li Yujie, Wang Mengshu, Xu Huijie et al. (2014) Study on the Damage Classification Criterion and Reinforcement Strategies of Mine Construction Subway. URBAN RAPID RAIL TRANSIT, 27 (1): 86-89.

[11] ZHONG Zhen-rong, LUO Ke-yan, YANG Shi-jiao et al. (2007) The Analysis and Treatment of the Track on Soil Bed Damage. Journal of East China University, 24 (2): 37-40.

[12] ZHAO Zhenjiang, QIAO Xiaolei. (2014) Mechanism and Prevention of the Monolithic Trackbed Disease Damage in Subway Tunnels. Urban Mass Transit, (12): 98-100. 
[13] Haorong, C., Limin, P., Mingfeng, L. et al. (2019) Causes Analysis, Reinforcement and Repair Technology of Segment Crack and Damage During Shield Tunnelling Process: A Case Study. Geotech Geol Eng 37, 765-773. https://doi.org/10.1007/s10706-018-0648-y.

[14] Ministry of Housing and Urban-Rural Development of the People's Republic of China. (2008) Code for construction and acceptance of shield tunneling method GB 50446-2008 [S]. China Architecture \& Building Press.

[15] A. Hillerborg, M. Modéer, P.-E. (1976) Petersson. Analysis of crack formation and crack growth in concrete by means of fracture mechanics and finite elements. Cement \& Concrete Research, 6 (6). 773-781.
[16] Yoo D Y, Yoon Y S. (2015) Structural performance of ultra-high-performance concrete beams with different steel fibers. Engineering Structures, 102 (NOV. 1): 409-423.

[17] Szab C, Hlb C, Yw B. (2019) Degradation behavior of concrete under corrosive coal mine environment. International Journal of Mining Science and Technology, 29 (2): 307-312.

[18] Li P, Liu H, Zhao Y, et al. (2018) A bottom-to-up drainage and water pressure reduction system for railway tunnels [J]. Tunnelling and Underground Space Technology, 81 (NOV.): 296-305. 